\title{
Singularidades toponímicas de las islas Pitiusas. La mediterraneidad de un paisaje insular a través de los nombres geográficos
}

\author{
Naming singularities of the Pine Islands. The Mediterranean nature \\ of an island landscape seen through geographical names
}

\author{
Antoni Ordinas Garau ${ }^{1^{*}}$ (i) \\ Jaume Binimelis Sebastián ${ }^{2}$ [D
}

\section{Resumen}

Este trabajo supone la continuidad en una línea de investigación iniciada en su aplicación a la isla de Menorca cuyo principal objetivo es constatar como el análisis de la toponimia constituye una importante fuente de información geográfica y en la que durante los últimos años se ha producido un importante auge en su estudio y producción científica. A partir del análisis cualitativo y cuantitativo del mayor corpus toponímico sobre el conjunto de las islas Pitiusas (Ibiza y Formentera) se constata el cumplimiento de los principios de transparencia y de significación territorial con los que se describen las características generales y las singularidades del paisaje y el espacio geográfico. La clasificación y sistematización de los nombres de lugar y sus genéricos más frecuentes y genuinos permiten ahondar en los rasgos más específicos y representativos de unas islas mediterráneas con una marcada identidad histórica y cultural. Es por ello que tanto la metodología como los resultados aquí obtenidos se ofrecen como modelo y contribución al avance de la geografía como ciencia innovadora en el aprovechamiento de la toponimia como herramienta del conocimiento territorial.

Palabras clave: Toponimia; clasificación; geografía; paisaje; islas Pitiusas; Ibiza; Formentera.

\begin{abstract}
This article continues an area of research undertaken and applied in Minorca and main aim is to verify how an analysis of names can provide an important source of geographical information. There has been a huge increase in naming or toponymy analysis in recent years. A qualitative and quantitative analysis of the largest corpus of names in the Pine Islands (Ibiza and Formentera) confirms compliance with the principles of transparency and territorial significance with which the general characteristics and singularities of the island landscapes are described. The classification and systematisation of place names and their most frequent and genuine generics enables us to delve into the most representative features of the distinct historical and cultural identity of these Mediterranean islands. Both the methodology and results are suggested as a template and contribution to progress to geography as an innovative science that uses names (or toponymy) as a tool for territorial knowledge.
\end{abstract}

Keywords: Toponymy; classification; geography; landscape; Pine islands; Ibiza; Formentera.

1 Departamento de Geografía. Universitat de les Illes Balears, España. antoni.ordinas@uib.es. * Autor para correspondencia

2 Departamento de Geografía. Universitat de les Illes Balears, España. jaume.binimelis@uib.es 


\section{Introducción: El trinomio toponimia-paisaje-geografía}

Han sido muchos los literatos —algunos tan célebres como Unamuno o Azorín-, en cuya obra está explícito el valor del paisaje como identidad cultural (Martínez de Pisón, 2010). Pero más allá de la mera contemplación a la que pueda invitar la belleza del paisaje, como disciplina científica, la Geografía analiza las relaciones entre el hombre y el medio físico que le rodea. De la confluencia de las fuerzas naturales y de las sociales surge el medio geográfico, cuya expresión es el paisaje. Cabe recordar que la disponibilidad de los recursos naturales condiciona la configuración territorial de los paisajes, que existen en tanto que son observados e interpretados por las sociedades humanas que a su vez los modelan. Concretamente, el paisaje no es más que una construcción histórica resultante de la interacción entre factores bióticos (vegetación y fauna) y abióticos (la interacción de las masas gaseosa, líquida y sólida, esencialmente) del medio natural, a los que se superponen los antrópicos. Por tanto, el paisaje es el resultado de una transformación colectiva de la naturaleza. La actividad humana crea los paisajes, modificando la sucesión natural y manteniendo estados antrópicos intermedios convenientes para sus fines. Y al respecto, los topónimos como una de las expresiones más humanas de los procesos de ocupación del medio y de la compleja construcción de los paisajes, se constituyen no sólo en referente también de la cartografía, instrumento propio del geógrafo, sino que también expresan una determinada organización del medio y del territorio. Aún más, la toponimia, en su papel de herramienta geográfica y humanística, permite al geógrafo demostrar su valor en la organización cultural de unos paisajes vividos a lo largo de milenios (Mateu, 2000).

La larga historia de impactos humanos en el paisaje es responsable de algunas de sus características distintivas que comprenden una transformación particularmente intensiva del territorio. El paisaje actual de las Islas Baleares es, por tanto, el resultado de la evolución natural y de la transformación producida por la humanidad desde hace más de 5.000 años y especialmente, por generaciones de agricultores y ganaderos. Esta larga intervención humana ha producido múltiples transformaciones que han dado lugar a una gran variedad de paisajes en muy poco espacio. De ahí que sea referido como microcosmos. Al margen de los paisajes más "naturales", aquellos en que la huella del hombre pasa más desapercibida, han sido las culturas agrarias quienes han conformado el escenario o marco espacio-temporal donde tienen lugar los procesos naturales y sociales. Este marco heredado de las generaciones pasadas y que es legado a las futuras es lo que se llama paisaje y sobre él seguimos construyendo la identidad personal y colectiva. Los paisajes baleares forman parte del mosaico mediterráneo, un mosaico de paisajes diversos, pues una de las originalidades de los paisajes humanos mediterráneos es su diversidad en los dos sentidos de la palabra: por una parte, organización de una diversidad de especies en cada paisaje; y por otra, paisajes varios donde cada uno de ellos se caracteriza por combinaciones distintas de especies adaptadas a las condiciones específicas de cada lugar: tipo de suelo y de relieves, pluviosidad y escorrentía, así como oscilaciones térmicas e insolación. De manera que, si desaparecen los agricultores, el paisaje puede sobrevivir durante un tiempo, pero como un paisaje muerto, como un paisaje fósil. En este contexto es cuando se aprecia el valor de la toponimia para interpretar la complejidad de los paisajes rurales (Mateu, 2000) al que se une la aplicación de los principios teóricos de transparencia, excepcionalidad y significatividad territorial enunciados por Tort (2001) y que suponen una de las principales aportaciones para la interpretación y análisis del paisaje a través de la toponimia, se convierten en guía y referencia para su aplicación al trinomio paisaje-toponimia-geografía. Y es que el propio mecanismo de fijación de los nombres de lugar explica su relevancia como indicadores de paisaje. Es más, los topónimos pueden identificar y reflejar aspectos de la cultura, el patrimonio y el paisaje, fruto de una estrecha y prolongada relación entre el territorio y sus habitantes, en un ejercicio que Riesco (2010) denomina mnemotecnia del paisaje.

Las relaciones entre toponimia, paisaje y geografía se conforman como los vértices de un triángulo por su estrecha interconexión. En un estudio previo que tenía por objeto el análisis del paisaje de Menorca a través de la toponimia (Ordinas y Binimelis, 2013) ya se expusieron los precedentes teóricos sobre los que se sustenta la intensa relación entre toponimia y geografía. A los datos y argumentos allí desarrollados sólo cabe subrayar que la numerosa y valiosa información transmitida por los topónimos puede proceder tanto por su parte genérica como por su parte determinante. En los genéricos o apelativos toponímicos aparece a menudo la terminología geográfica que describe las características generales del país, mientras que en los determinantes de los topónimos abundan los detalles específicos que ahondan en la información particular de cada lugar denominado aportando un amplio abanico de potencialidades referidas a múltiples aspectos de carácter muy diverso (geográfico, histórico, antroponímico...). Al respecto, resultan especialmente ilustrativas las palabras del ibicenco Marià Torres (1995) al remarcar el valor enciclopédico o interdisciplinar que brota de la toponimia: personas, hechos históricos, plantas y animales, pesca y navegación, la morfología del terreno, religiosidad y superstición, aspectos que recogen el amplio espacio 
que existe entre el hombre y la naturaleza. Asimismo, y más allá de la amplia interdisciplinariedad que atañe la toponimia, interesa destacar cómo los nombres de lugar de un territorio constituyen un fiel reflejo de las interrelaciones entre los aspectos físicos y humanos del mismo, de su evolución y de su paisaje. Su objetivo esencial es definir el orden y la coherencia espacial que revela la red de topónimos de una comarca o región a través de la observación como base de la interpretación toponímica (Arroyo, 2010).

Retomando la esencia de los nombres de lugar, Martínez de Pisón (2010) recuerda tanto la función identificadora como la descriptiva que éstos aúnan cuando afirma que:

La toponimia no es sólo una especialidad lingüística ni un repertorio de nombres azarosos, sino también y muy directamente una referencia geográfica. Primero para designar puntos, y sobre todo porque encierra un enigma y pide una explicación coherente con los hechos territoriales, los de hoy $\mathrm{o}$, más frecuentemente, los de ayer. Porque es un documento clave de la historia de una relación territorial. Esto lo sabían antes los geógrafos, no era necesario decirlo, pero hoy es preciso volver a ejercitarlo (Martínez de Pisón, 2010, p. 24-25).

Y como señala Riesco (2010),

El encuadre metodológico de los paisajes históricos (...) tiene en cuenta la toponimia documental y oral. (...) El espesor histórico de un área paisajística, esto es, la sucesiva imprimación del territorio por la actividad humana desde siglos remotos, es una de las claves del carácter de los paisajes; la reconstrucción de paisajes antiguos saca partido de los nombres de lugar, combinados con aportaciones de la arqueología, antropología, historia, socio-ecología y otras disciplinas concurrentes. (p. 27)

Una de sus aplicaciones más claras se encuentra en el paisaje vegetal, donde el estudio toponímico permite comprobar la riqueza y alto grado de contingencia de las evoluciones seguidas (Fernández, Gómez-Gonçalves, y Luengo, 2019). Así se ha podido corroborar en diversos estudios realizados sobre la fitotoponimia del paisaje natural menorquín (Grimalt, Ordinas, Caldentey, 2009) y también sobre el paisaje vitícola actual e histórico de Mallorca (Caldentey, Grimalt, Ordinas, 2006).

Por otro lado, y entroncando con la utilización cartográfica de la toponimia, permite abordar el estudio histórico del paisaje, pues los topónimos sobre el mapa sirven al geógrafo para rescatar paisajes perdidos de forma que "el conocimiento histórico sumado al del terreno (...) permiten identificar sus significados paisajísticos y sus sencillas conceptualizaciones de los lugares. Por ello se afirma que la toponimia es parte de la historia del paisaje" (Martínez de Pisón, 2010, p. 17). De hecho, al acometer la complejidad de la casuística toponímica en sus aplicaciones cartográficas, también descubrimos la mayor riqueza y articulación de la toponimia menor o microtoponimia en la descripción paisajística, así como su densidad y distribución en la que se producen superposiciones, solapamientos y casos de topónimos que incluyan otros subtopónimos. Tampoco resulta extraño que un mismo lugar pueda recibir distintas denominaciones que rivalizan y conviven temporalmente como resultado de una implantación sucesiva. En ocasiones, paralelamente a los nombres más o menos oficiales existen nombres afectivos, menos conocidos, de carácter y uso familiar de propietarios y vecinos. En otras, los herederos de tierras con vínculos familiares antiguos respetan los nombres arcaicos. Esta actitud contrasta con la de los nuevos propietarios que implantan neotopónimos en un ejercicio de innovación cada vez más extendido, pero incompatible con la preservación de un patrimonio cultural intangible y escasamente protegido como el de la toponimia. Sin duda, el fenómeno de la doble, o triple, denominación conlleva implicaciones sociolingüísticas entre las que destaca la retoponimización (Riesco, 2010) que se traduce en una neotoponimia rururbanizadora y turística y que no deja de ser un reflejo de los valores y la cultura de la sociedad contemporánea.

Por otra parte, es importante reseñar la aplicación de la toponimia como técnica auxiliar en la descripción de cambios en el paisaje, así como de su identidad y simbología. Las alusiones al color en los topónimos, los cromotopónimos, aportan información visual del paisaje al que se refieren. En un estudio sobre la cromotoponimia de las Baleares (Ordinas y Binimelis, 2020) se descubren los colores de mayor presencia en la toponimia que, en el caso de Ibiza donde abundan las alusiones al negro y al verde, no se amoldan a los estereotipos turísticos, no exentos de cierto glamur, que la asocian a la isla blanca por las tradicionales edificaciones rurales, de arquitectura cúbica de origen púnico, y de paredes encaladas que tanto caracterizan el paisaje mediterráneo.

\subsection{La toponimia pitiusa. Estudios previos}

El estudio de la toponimia pitiusa y, más concretamente, ibicenca y/o formenterera no puede desvincularse en muchos casos de estudios de ámbito más general, como el balear, en los que el territorio del 
subarchipiélago es incluido al formar parte de circunscripciones territoriales, lingüísticas y culturales más amplias. No obstante, la recopilación y estudio de la toponimia pitiusa, en un sentido vasto y generalizado, se abordó en fechas relativamente recientes y sólo de forma puntual y parcial, pero nunca, al menos a lo largo de una primera etapa, en su conjunto a partir de recopilaciones toponímicas exhaustivas3. No obstante, el análisis y estudio lingüístico de algunos topónimos ya queda reflejado en diversas publicaciones que van apareciendo en una primera etapa que se desarrolla durante las décadas de los 60 y 70 del siglo XX y cuyos autores son mayoritariamente ibicencos. Dicha etapa se inicia con un artículo de Joan Castelló (1963) sobre la toponimia de Ibiza y Formentera y que tendrá continuidad en las diversas aportaciones sobre etimologías toponímicas realizadas por Isidor Macabich (1966a, 1966b, 1966c, 1966d, 1966e, 1966f, 1966g, 1966h, 1966i) en su Historia de Ibiza. Marià Villangómez (1969, 1977a, 1977b) también contribuye al estudio de topónimos ibicencos en algunos artículos publicados entre 1969 y 1977. Cerrando la década de los setenta, destaca un artículo de Isidor Marí (1979) sobre la toponimia básica de las Pitiusas.

En los años ochenta comienza una nueva etapa, más prolífica, que se inicia con un estudio sobre la toponimia formenterera (Gordillo, 1981) al que se sumarán otros de Àngel Poveda (1984) y Martínez y Epalza (1987), ambos sobre la arabización de la toponimia pitiusa. También a esa década pertenecen las diversas obras de Cosme Aguiló (1986, 1989, 1990, 1993a, 1993b), algunas de las cuales prolongan su publicación en la década de los 90 y de las que destaca el mapa toponímico de los islotes pitiusos (Aguiló, 1987). En 1989 comienza a editarse la Enciclopèdia d'Eivissa i Formentera, obra magna donde ya aparece, en temas toponímicos y entre otras, la autoría de Enric Ribes, cuya vasta e importante obra sobre múltiples aspectos y recopilaciones toponímicas de las Pitiusas iniciada en los años 80 y aún vigente, le convierte en su principal referente (Ribes, 1986, 1991, 1992a, 1992b, 1992c, 1993a, 1993b, 1993c). Destacan sus recopilaciones exhaustivas de la toponimia litoral correspondiente a los municipios de Sant Joan de Labritja, Sant Antoni de Portmany y Eivissa (Ribes, 1993d, 1995 y 2006). Por último y entre otras4, cabe citar diversas contribuciones sobre antiguos topónimos isleños (Marí Cardona, 1991), la antropotoponimia de Formentera (Ordinas, 1994) o a la utilidad didáctica de la toponimia pitiusa y otros aspectos culturales (Torres, 1987 y 1995).

\subsection{Objetivos}

El principal objetivo de este trabajo es el de constatar como la toponimia es un magnífico instrumento para la lectura del paisaje a la vez que constituye una importante fuente de información geográfica cuyas potencialidades se descubren a través de su análisis y como resultado de su previa clasificación. Más específicamente, se pretende constatar el cumplimiento de los principios de transparencia y de significación territorial con los que se describen las características generales y las singularidades del paisaje y el espacio geográfico, en este caso, de las Islas Pitiusas. Asimismo, también se pretende profundizar en el estudio de la caracterización del paisaje a través de la toponimia del archipiélago balear que iniciamos con la isla de Menorca (Ordinas y Binimelis, 2013) y que ahora tiene su continuidad en el subarchipiélago pitiuso (Ibiza y Formentera). La separación al abordar ambos análisis se debe tanto al ingente volumen de datos toponímicos que cada uno de estos territorios genera como a las diferentes identidades geográficas de sus respectivos paisajes insulares.

Finalmente, la clasificación y sistematización de los nombres de lugar y sus genéricos más frecuentes y genuinos ha de permitirnos ahondar en los rasgos más específicos y representativos de unas islas mediterráneas con una marcada identidad histórica y cultural.

\section{Metodología}

\subsection{El área de estudio: las islas Pitiusas, un subarchipiélago con identidad propia}

Las islas Baleares, situadas en el centro-oeste del sector occidental del Mar Mediterráneo, constituyen un archipiélago formado por cinco islas mayores (Mallorca, Menorca, Ibiza, Formentera y Cabrera ${ }^{5}$ y más de 150 islas menores e islotes con una extensión total de 4.968,3 $\mathrm{km}^{2}$ y una longitud de costa, en su conjunto, de $1.428 \mathrm{~km}$ (Figura 1). Las islas de Mallorca, Menorca, Cabrera y sa Dragonera junto con sus

\footnotetext{
3 Lamentablemente, la meritoria labor de Josep Mascaró Passarius, precursor balear en recopilaciones toponímicas, quien recogería buena parte de la toponimia de las islas de Menorca y de Mallorca a mitad del siglo XX, no alcanzó, sin embargo, las tierras pitiusas.

4 En varias publicaciones (Ordinas, 1998) se recoge la bibliografía específica sobre la toponimia pitiusa publicada hasta la fecha.

5 Tanto Cabrera como sa Dragonera, por sus reducidas dimensiones, históricamente han permanecido prácticamente deshabitadas. En el caso de Cabrera se trata de un subarchipiélago formado por 19 islas e islotes de apenas $13 \mathrm{~km}^{2}$.
} 
islotes adyacentes forman el subconjunto que desde el punto de vista histórico genuino se denominaban Islas Baleares (o Gimnesias), mientras que Ibiza, Formentera y sus islotes ${ }^{6}$ forman las islas Pitiusas.

Figura 1. Situación geográfica del archipiélago pitiuso

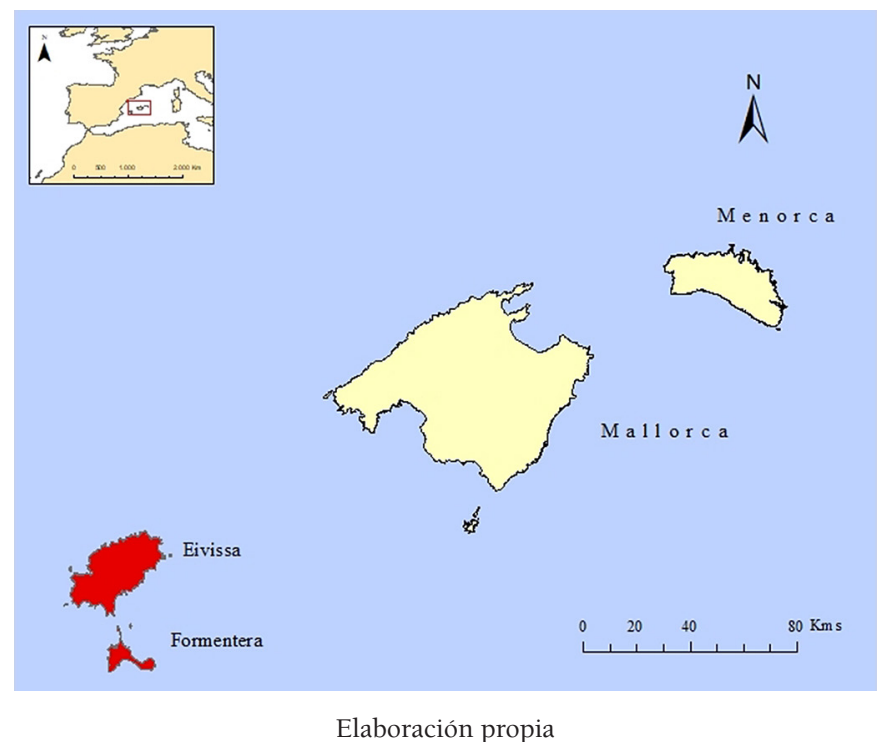

Las Pitiusas constituyen, por tanto, un subarchipiélago de $654,2 \mathrm{~km}^{2}$ que ocupa el sector sud-occidental del archipiélago balear, situándose en el extremo nordeste de las sierras sub-béticas, de cuyo territorio peninsular se encuentran más próximas lo que ha supuesto un mayor contacto comercial y humano; y más alejadas ${ }^{7}$, en cambio, de las antiguas Baleares (Mallorca y Menorca). Esta situación geográfica ha condicionado la vida y la cultura pitiusas a lo largo de la historia.

La isla de Ibiza $\left(571,7 \mathrm{~km}^{2}\right.$ y $334 \mathrm{~km}$ de costa) se orienta de NE a SO con una distancia máxima de 41 $\mathrm{km}$ entre sus extremos. En ambos se encuentran los dos conjuntos montañosos más importantes, separados por un área cóncava por donde discurren los torrentes que mayoritariamente drenan hacia el sur. En el área del SO se alza sa Talaiassa o Talaia de Sant Josep (475 m) (Figura 2), la máxima altitud isleña. La costa ibicenca se articula en numerosas calas, en cuyo fondo se descubren playas de arena o de guijarros (es Codolar/Platja des Còdols), y dos bahías, la de Sant Antoni de Portmany y la de Ibiza, situadas en los extremos de una franja deprimida que separa las áreas de mayor relieve. Predominan los materiales calcáreos y sus manifestaciones cársticas (lapiaz, cuevas, simas), destacando los poljes que originan algunos valles sin drenaje superficial (Pla de Corona, Pla d'Albarca).

Un canal de $6 \mathrm{~km}$ jalonado por numerosos islotes separa Ibiza de Formentera, la pitiusa menor, de apenas $82,4 \mathrm{~km}^{2}$ y $115,2 \mathrm{~km}$ de costa. Formada por dos macizos opuestos: la Mola (122 m) y el cap de Barbaria $^{9}(107 \mathrm{~m})$ comunicados por un istmo en cuyos lados se extienden largas playas arenosas (Figura 3), carece de una red hidrológica a causa de su régimen pluviométrico, el más escaso de las Baleares. Tales características, que marcan su personalidad, se remontan a su origen histórico que data del siglo VII aC cuando los cartagineses iniciaron la explotación de sus salinas y fundaron la ciudad de Ebusus ${ }^{10}$ en una isla que hasta entonces no había tenido población estable. Las reducidas dimensiones insulares favorecieron desde un principio la macrocefalia de su ciudad ${ }^{11}$ cuyo monopolio urbano ya contrastaba con el resto del territorio de escasa población.

6 En la costa de Ibiza se contabilizan un total de 38 islotes entre los que destacan sa Conillera, s'Espartar, illa des Bosc, Tagomago, es Vedrà y es Vedranell. Próximos a Formentera se sitúan otros 14 islotes entre los que sobresalen s'Espalmador y s'Espardell.

7 La distancia mínima que separa las islas de Mallorca e Ibiza es de $81 \mathrm{~km}$.

8 Su etimología, del latín 'portus magnus', así también lo indica.

9 El topónimo obedece a su orientación hacia las cercanas costas del norte de África, siendo el punto extremo sur del archipiélago balear con una latitud de 38'38'25.39'N.

10 El topónimo procede de la antigua denominación fenicia 'Y-b-š- $m$, 'isla de Bes', en alusión a esta deidad del panteón fenicio, aunque de origen egipcio.

11 Tanto la simpleza de su modesta denominación popular, Vila (villa), que ya la define implícitamente como su único núcleo urbano, como la coincidencia toponímica entre el nombre de la isla y de la ciudad refuerzan la total identificación del conjunto de la isla con su ciudad siguiendo el modelo de las polis o ciudades-estado mediterráneas del mundo antiguo. 
Figura 2. Talaia designa los montes que sirvieron de observatorios en los lejanos tiempos en que el peligro de invasiones piráticas era frecuente (Castelló 1963). No en balde la máxima altura de la isla (475 m) se denomina Talaia de Sant Josep o sa Talaiassa

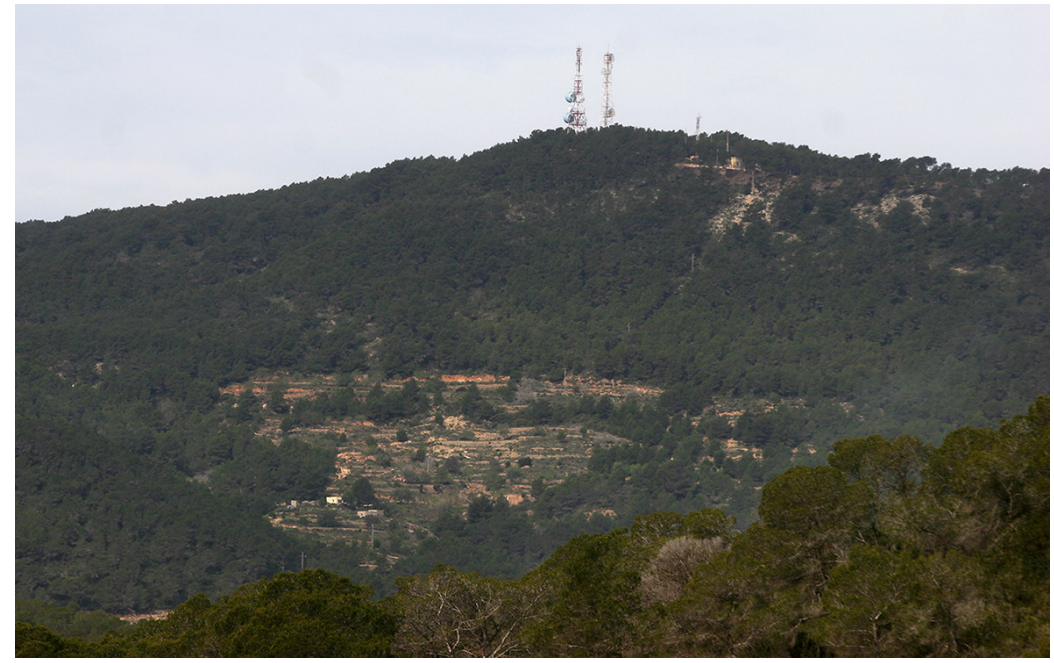

Fotografía de los autores

Figura 3. En Formentera, desde la máxima altitud de la Mola (202 m) se extiende un istmo bordeado por extensas playas de cristalinas aguas

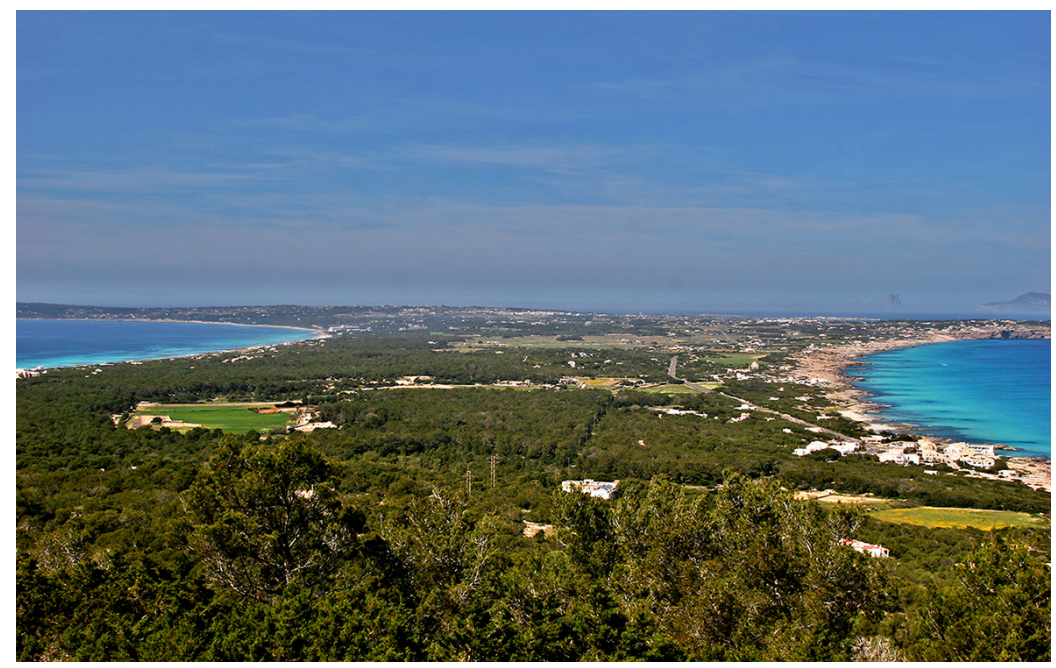

Fotografía de los autores

Son casi imperceptibles las diferencias que se pueden señalar entre las dos islas pitiusas. La reducida proporción territorial y la tardía ocupación histórica de Formentera por su indefensa exposición a ataques e invasiones exteriores, la han convertido en un apéndice cultural —en concordancia con su posición geográfica- de su cercana metrópolis de Ibiza. Frente a la despoblación secular del pasado, a tenor del desarrollo turístico Formentera ha experimentado un importante crecimiento poblacional que llega a la saturación en la época veraniega, cuando los turistas prácticamente colapsan sus playas. La riqueza generada por la actividad turística ha supuesto la consecución de una mayor autonomía político-administrativa frente al poder centrípeto de la cercana Ibiza y también del centralismo balear personificado en Mallorca. A pesar, no obstante, de las ya señaladas escasas y lógicas diferencias entre las dos islas Pitiusas.

El paisaje de las Pitiusas, aunque refleja aspectos que lo diferencian del de las Gimnesias, resulta, sin embargo, menos diverso por su menor extensión. Destaca, por su mayor personalidad, la región de es Amunts, al norte de Ibiza, la más alejada de la capital, de orografía más abrupta y menor densidad de población. No obstante, la práctica totalidad del territorio insular se caracteriza por un poblamiento rural muy diseminado acorde con una estructura minifundista de la propiedad. Todo ello favorece el policultivo 
cuyo protagonista es el arbolado mediterráneo (almendro, algarrobo, olivo, higuera) compatible con una práctica ganadera extensiva de ovino y caprino. En unas islas donde tradicionalmente se exigía la autarquía, no faltaban pequeñas zonas de huerta de regadío, destacando el área de ses Feixes (Figura 4), muy próxima a la capital, Eivissa. Formentera, por su parte, despoblada durante siglos por su desprotección ante ataques de piratas y corsarios, constituye un apéndice paisajístico de la cercana Pitiusa mayor y en la que la omnipresencia del mar circundante junto a unas condiciones climáticas más severas, sólo permiten destacar las higueras de copas frondosas y apuntaladas como símbolo más representativo de un paisaje de agricultura de secano.

Figura 4. En un área pantanosa próxima a la ciudad de Ibiza, un típico portal de feixa, un tradicional paisaje de regadío por endosmosis, actualmente abandonado

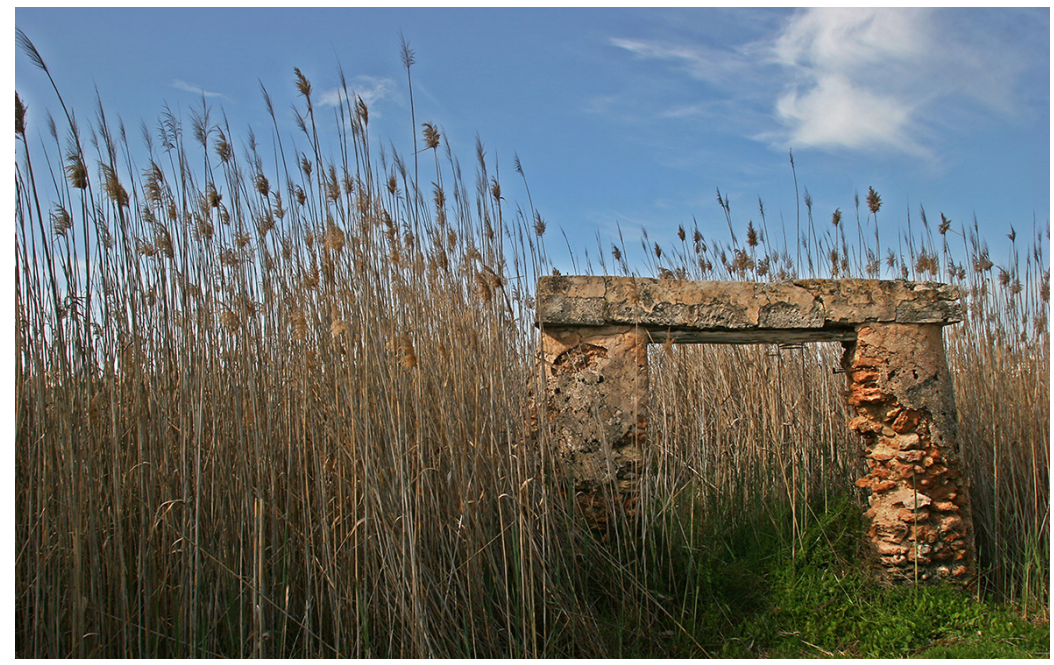

Fotografía de los autores

No obstante, el importante desarrollo de la actividad turística iniciada a partir de los años sesenta y que supuso la llegada de los primeros hippies se tradujo en una progresiva urbanización del litoral (Figura 5) y la rururbanización del interior, transformando buena parte del paisaje isleño. Los fuertes impactos de la terciarización y la especialización turística han proyectado una imagen cosmopolita que ha eclipsado la cultura tradicional. Tales cambios también se han visto reflejados en la toponimia, con la abundante aparición de neotopónimos (Picornell, 1982) surgidos ante los nuevos usos de un territorio sometido a la fuerte presión del turismo de masas.

Figura 5. La platja d'en Bossa, en el municipio de Ibiza, un enclave paradigmático del turismo de sol y playa

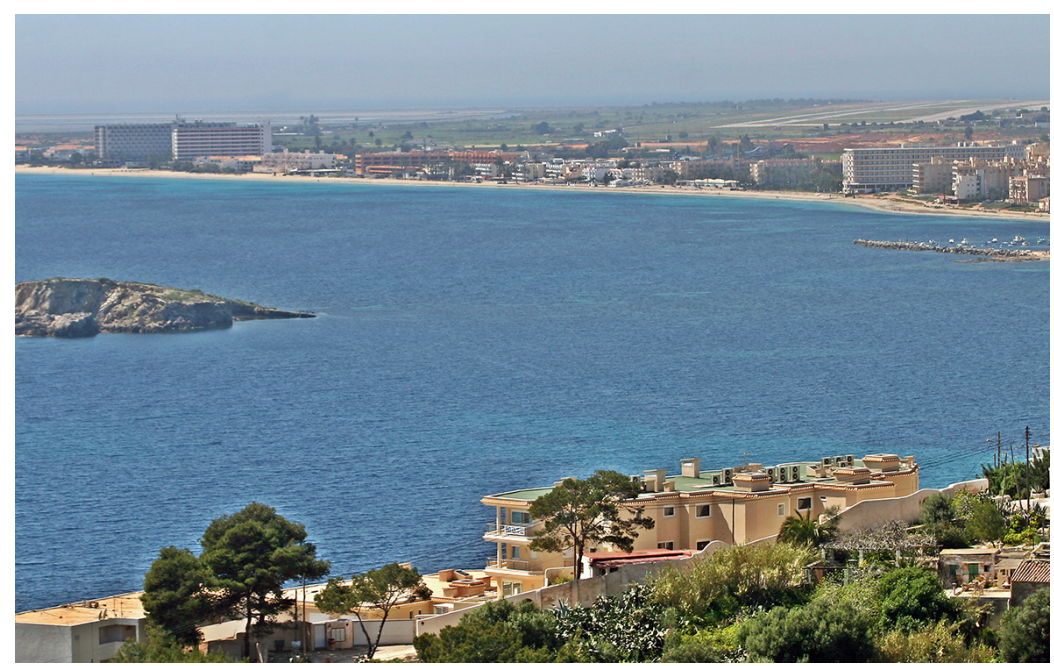

Fotografía de los autores 


\subsection{Fuente y métodos}

Se ha analizado el mayor corpus toponímico hasta ahora obtenido de las islas Pitiusas en cuya recolección uno de los autores participó personalmente. Se trata de la toponimia obtenida para vestir el Mapa Topográfico Balear a escala 1:5.000 con cuyo trabajo de campo (Tabla 1) se consiguieron reunir 7.731 topónimos, cifra de la que se deriva una densidad media de 11,8 topónimos $/ \mathrm{km}^{2}$ como resultado de las entrevistas realizadas sobre el terreno a numerosos informadores, seleccionados por su especial conocimiento de una determinada área del territorio sobre la que fueron interpelados.

Tabla 1. Datos relativos al corpus toponímico de las islas Pitiusas

\begin{tabular}{|l|c|c|c|}
\hline & Ibiza & Formentera & Pitiusas \\
\hline Superficie $\left(\mathrm{km}^{2}\right)$ & 571,76 & 82,49 & 654,25 \\
\hline Topónimos & 6.710 & 1.021 & 7.731 \\
\hline Densidad (topónimos/km²) & 11,7 & 12,3 & 11,8 \\
\hline
\end{tabular}

Elaboración propia

Siguiendo la metodología utilizada en el análisis de la toponimia de Menorca, se ha clasificado y contabilizado la toponimia de las islas Pitiusas a partir de la codificación del Institut Cartogràfic de Catalunya (ICC), organismo encargado de la coordinación de la recopilación toponímica del Mapa Topográfico Balear a escala 1:5.000 cuyos resultados se muestran en la Tabla 1. La rotulación cartográfica de la toponimia exige su codificación y para ello cada uno de los topónimos debe ser clasificado atendiendo a diversos parámetros entre los que destacan el de su magnitud (extensión, longitud, altura...) y el de su identificación o realidad geográfica que no siempre se corresponde con la que su apelativo toponímico indica y prestándose, en tales casos, a un claro equívoco. Así pues, la propuesta de codificación del ICC, organismo encargado del levantamiento del mapa, es la utilizada para nuestro estudio y a través de la que podemos conocer, mediante un análisis cuantitativo de la distribución temática de los topónimos que nos ofrece su clasificación, las principales características geográficas del conjunto de la toponimia pitiusa. La jerarquización toponímica mediante el número de frecuencias y su porcentaje correspondiente, permite alcanzar un nivel de análisis más detallado. Para ello, hemos seleccionado las categorías toponímicas que presentaban las frecuencias más elevadas de las entradas de la codificación. La Tabla 2 refleja dicha clasificación, así como los datos generales del recuento toponímico relativo a las islas Pitiusas en su conjunto y de cada una de las islas (Ibiza y Formentera) por separado.

Tabla 2. Recuento y clasificación de la toponimia de las islas Pitiusas

\begin{tabular}{|l|c|c|c|}
\hline \multicolumn{1}{|c|}{ Topónimos relativos a: } & Ibiza & Formentera & Pitiusas \\
\hline Lugares de habitación permanente & $3.845(57,3 \%)$ & $511(50 \%)$ & $4.356(56,3 \%)$ \\
\hline Implantación industrial & $21(0,3 \%)$ & $5(0,4 \%)$ & $26(0,3 \%)$ \\
\hline Servicios de comunicación y transporte & $190(2,8 \%)$ & $42(4,1 \%)$ & $232(3 \%)$ \\
\hline Servicios comunitarios & $104(1,5 \%)$ & $16(1,5 \%)$ & $120(1,5 \%)$ \\
\hline POBLAMIENTO & $4.160(62 \%)$ & $574(56,2 \%)$ & $4.734(61,2 \%)$ \\
\hline Orografía terrestre y marítima & $1.981(29,5 \%)$ & $391(38,3 \%)$ & $2.372(30,6 \%)$ \\
\hline Hidrografía & $569(8,4 \%)$ & $56(5,4 \%)$ & $625(8 \%)$ \\
\hline MEDIO FíSICO & $2.550(38, \%)$ & $447(43,7 \%)$ & $2.997(38,7 \%)$ \\
\hline TOTAL & $6.710(86,8 \%)$ & $1.021(13,2 \%)$ & $7.731(100 \%)$ \\
\hline
\end{tabular}

Elaboración propia

\section{Resultados: los topónimos en el paisaje pitiuso}

A partir de la tradicional división que en Geografía distingue entre medio físico y humano se observa, como rasgo fundamental, la superioridad de la toponimia relativa al poblamiento $(61,2 \%)$ frente a la del 
medio físico $(38,7 \%)$, datos que resultan muy significativos respecto al paisaje pitiuso y que contrastan con los del menorquín, donde se observa una realidad totalmente opuesta. En la Tabla 2 aparecen detalladas las cifras absolutas y sus respectivos porcentajes que permiten profundizar en la descripción de un territorio insular con características propias.

\subsection{La toponimia relativa al poblamiento}

Entre los topónimos referidos al poblamiento se distinguen cuatro grupos de muy desigual peso (Figura 6), destacando el de los lugares de habitación con un 92\%, muy alejado del resto de los nombres geográficos referidos a servicios de comunicación y transporte, servicios comunitarios e implantación industrial cuyos respectivos porcentajes se reducen a un $5 \%, 2 \%$ y $1 \%$, respectivamente.

Figura 6. Toponimia relativa al poblamiento

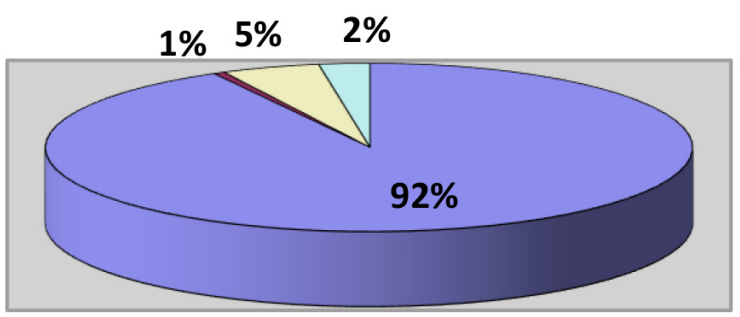

\section{$\square$ Lugares de habitación \\ $\square$ Implantación industrial \\ $\square$ Servicios de comunicación y transporte \\ $\square$ Servicios comunitarios}

Elaboración propia

\subsubsection{Lugares de habitación}

Constituyen el grupo mayoritario tanto entre los topónimos indicadores del poblamiento como en el conjunto de la toponimia pitiusa $(56,3 \%)$. Se dividen en tres subgrupos: los relativos a núcleos de población, partes de un núcleo urbano y edificaciones aisladas. En la Figura 7 se observa como destaca con un 94\% éste último, cuya plasmación paisajística se evidencia claramente en la Figura 8. La abundancia de pequeñas propiedades, producto de una tradicional y repetida fragmentación como consecuencia del legado de generaciones, donde se levanta una vivienda unifamiliar permanente ha dado lugar a su característico poblamiento intensamente diseminado, el más acusado de las Baleares y que contrasta con el de ciertas áreas de Mallorca y Menorca en su conjunto.

El resto de subgrupos apenas reúnen el 6\% de los topónimos de este apartado, de los cuales un 4\% corresponden a núcleos de población que agrupan a ciudades, pueblos y urbanizaciones. La insignificancia del subgrupo relativo a las partes de un núcleo urbano (1\%) donde se incluyen los barrios, avenidas, paseos y plazas más importantes se debe en buena parte a que la recolección toponímica de carácter urbano ha sido muy selectiva y reducida, condicionada por el carácter topográfico de la cartografía a la que iba destinada la recolección toponímica. Por último, suman el restante 1\% las edificaciones secundarias, también aisladas y no siempre habitadas de forma permanente (barracas, cabañas).

Figura 7. Toponimia relativa a lugares de habitación

$1 \% \quad 4 \% \quad 1 \%$

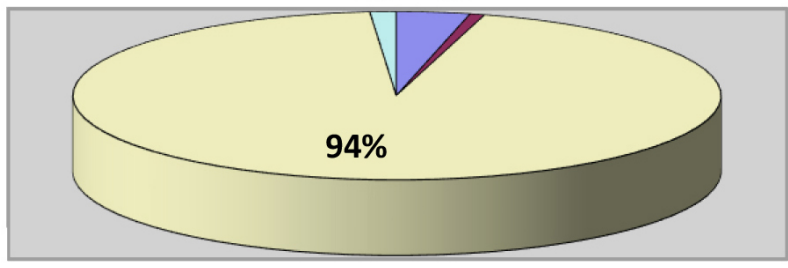

Elaboración propia

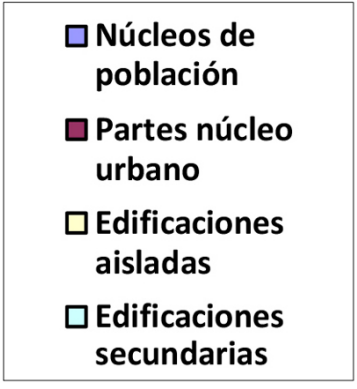


Figura 8. Poblamiento diseminado, fruto de una densa rururbanización, en el municipio de Sant Antoni de Portmany. Al fondo, junto a la bahía, su núcleo urbano

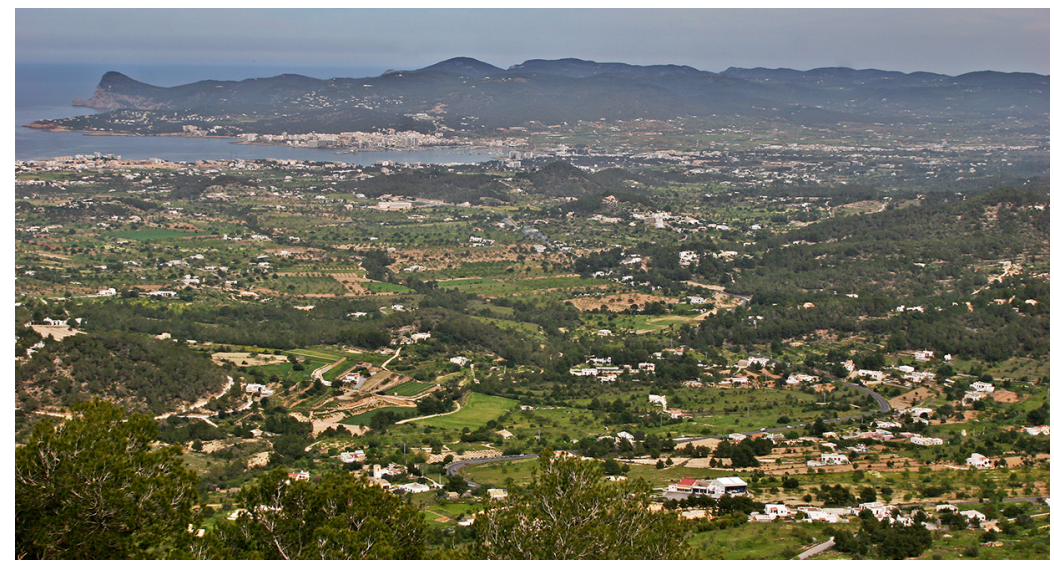

Fotografía de los autores

\subsubsection{Implantación industrial}

Sólo un 1\% de este grupo (que se reduce al 0,3\% del total de los topónimos) supone la representación toponímica que corresponde a la implantación industrial. Ello es debido no sólo a la escasa presencia industrial en las islas sino también a que la mayor parte de los nombres de lugar que su actividad genera resultan ser microtopónimos y neotopónimos de carácter comercial que frecuentemente aluden a marcas cuya publicidad no se adecúa a las características de un mapa topográfico oficial ni consiguen el arraigo y perdurabilidad toponímicas, por lo que resulta desaconsejable su inclusión en la cartografía cuya toponimia constituye la fuente del presente estudio. En cualquier caso, la irrelevancia del sector industrial y, en consecuencia, de su nomenclatura geográfica se extiende al conjunto del archipiélago balear, aunque las Pitiusas son el territorio que acusa la mayor escasez.

\subsubsection{Servicios de comunicación y transporte}

Sólo el 3\% de los topónimos pertenecen a este subgrupo y una amplia mayoría de ellos (91\%) corresponde a vías de comunicación (carreteras, caminos, puentes, túneles...), en las que caminos y carreteras resultan mayoritarios. Aunque también se incluyen los topónimos referidos a otras instalaciones para los medios de transporte, en general, así como los relacionados con el tráfico aéreo, su representación toponímica es exigua. En cambio, como lógica consecuencia de su insularidad, los topónimos relativos al tráfico marítimo alcanzan un 9\% de su grupo (Figura 9).

Figura 9. Toponimia relativa a servicios de comunicación y transporte

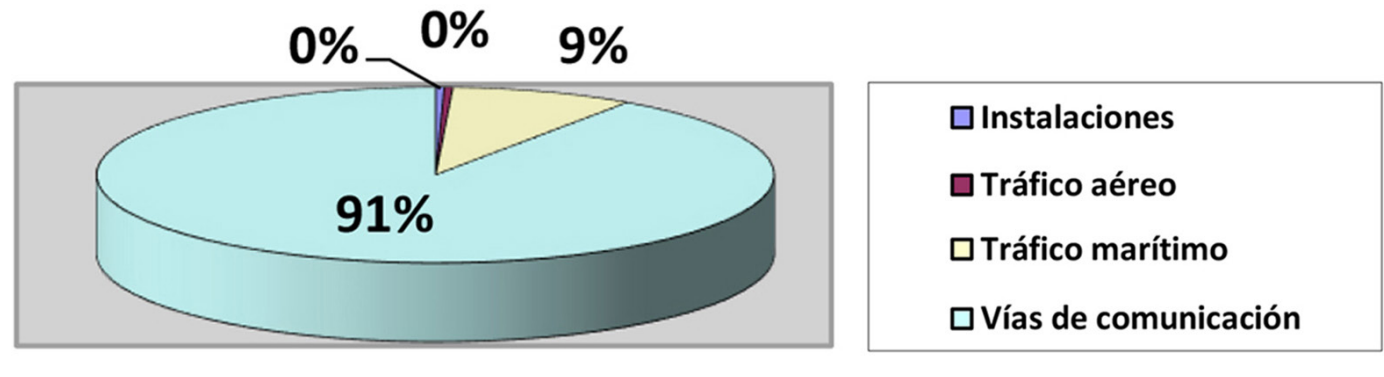

Elaboración propia

\subsubsection{Servicios comunitarios}

Finalmente, un último subgrupo entre los topónimos relativos al poblamiento lo constituyen los relacionados con los servicios comunitarios que, en conjunto, suponen un 1,5\%. Su escasa representatividad se acentúa por su atomización en ocho apartados. Los de mayor representación son los referidos 
a lugares de interés histórico-cultural, centros docentes, centros religiosos y centros de ocio (Figura 10). En el otro extremo, con una menor presencia, se sitúan los centros de servicios sociales, administrativos, comerciales y sanitarios.

Figura 10. Toponimia relativa a servicios comunitarios

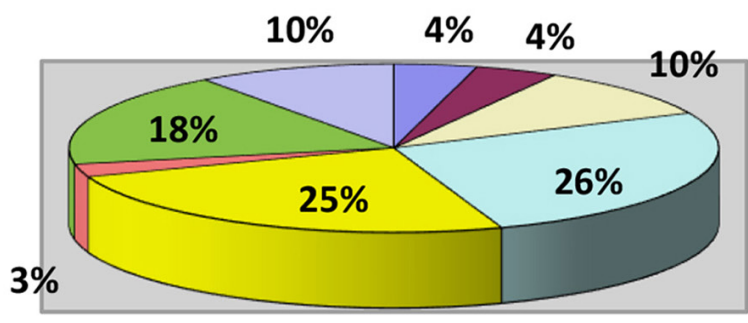

\section{$\square$ Centros administrativos}

$\square$ Centros comerciales

$\square$ Centros servicios sociales

$\square$ Lugares de interés históricocultural

$\square$ Centros docentes

$\square$ Centros sanitarios

$\square$ Centros religiosos

Elaboración propia

\subsection{La toponimia relativa al medio físico}

El medio físico, al que va referida el $38,7 \%$ de la toponimia pitiusa, se encuentra dividido en dos grandes bloques de desigual representación (Figura 11). Se trata de la orografía terrestre y marítima (79\%) y la hidrografía (21\%). Antes de entrar en el detalle pormenorizado de estos últimos datos, cabe destacar no sólo el acusado desequilibrio entre la toponimia correspondiente al medio físico y la del poblamiento y, más aún, cuando en el resto del territorio balear y especialmente en el caso de Menorca (Ordinas y Binimelis, 2013) sucede todo lo contrario. La explicación de los porcentajes de la toponimia pitiusa reside sobre todo en el sobredimensionamiento de la toponimia relativa al poblamiento en diseminado y no en una infranomenclatura toponímica del medio físico que, por otra parte, es abundante tanto por las características geomorfológicas de las islas como por su articulado y extenso litoral con un total de $449,2 \mathrm{~km}$.

Figura 11. Toponimia relativa al medio físico

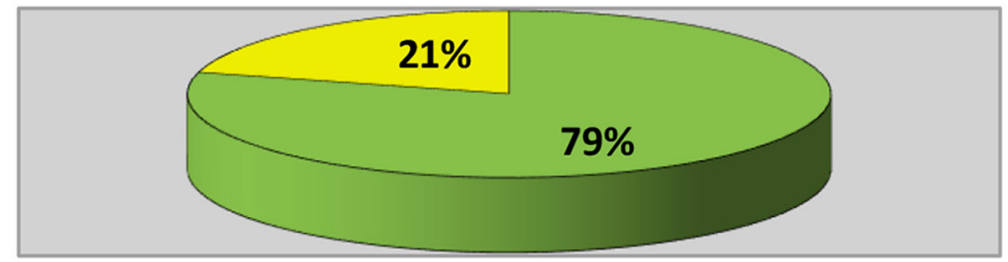

\begin{tabular}{|l|}
\hline \\
$\begin{array}{l}\text { Orografía terrestre y } \\
\text { marítima }\end{array}$ \\
$\square$ Hidrografía
\end{tabular}

Elaboración propia

\subsubsection{Orografía terrestre y marítima}

La oronimia pitiusa supone el 30,6\% del total (con importantes diferencias entre Ibiza, con un 29,5\% y Formentera con un 38,3\%). Su conjunto (Figura 12) incluye hasta diez tipologías orográficas: elevaciones del terreno en general, montañas y/o puntos elevados de una montaña, depresiones de la superficie terrestre, pasos a través de una cresta, acantilados, terrenos llanos, terrenos en pendiente, cavidades naturales, áreas, y relieves litorales marinos. El recuento descubre el predominio de la toponimia litoral (38\%) seguido de las áreas (18\%), las prominencias que culminan en los puntos más elevados de una montaña (17\%) y las elevaciones del terreno (12\%) que incluye macizos, montañas, sierras, cordilleras, colinas, cerros, etc. Todo ello desvela de forma fidedigna algunos de los rasgos básicos del paisaje pitiuso, donde destaca la costa (Figura 13) y la omnipresente orografía interior. Juegan, en cambio, un papel más secundario las depresiones (6\%), el terreno llano (4\%), las cavidades naturales (3\%), los acantilados (1\%) y el terreno en pendiente ( $1 \%)$. 
Figura 12. Toponimia relativa a la orografía terrestre y marítima

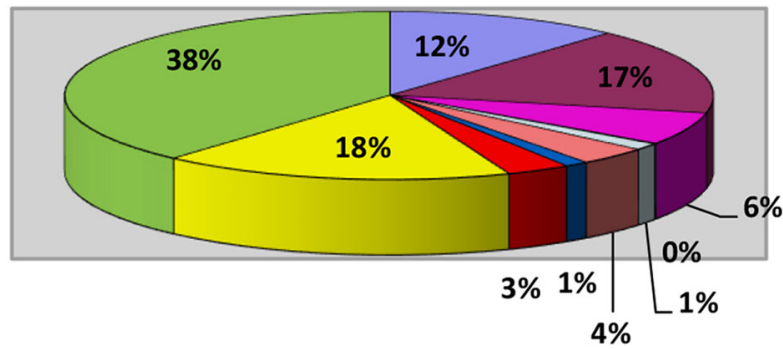

$\square$ Elevaciones del terreno
$\square$ Puntos elevados de montaña
$\square$ Depresiones
$\square$ Pasos
$\square$ Acantilados
$\square$ Terreno llano
$\square$ Terreno en pendiente
$\square$ Cavidades naturales
$\square$ Áreas
$\square$ Relieve litoral y marino

Elaboración propia

Figura 13. Desde el faro del Cap de Barbaria (Formentera), enclave más meridional del archipiélago, como ya indica el propio topónimo, se otea el mar que baña las costas norteafricanas

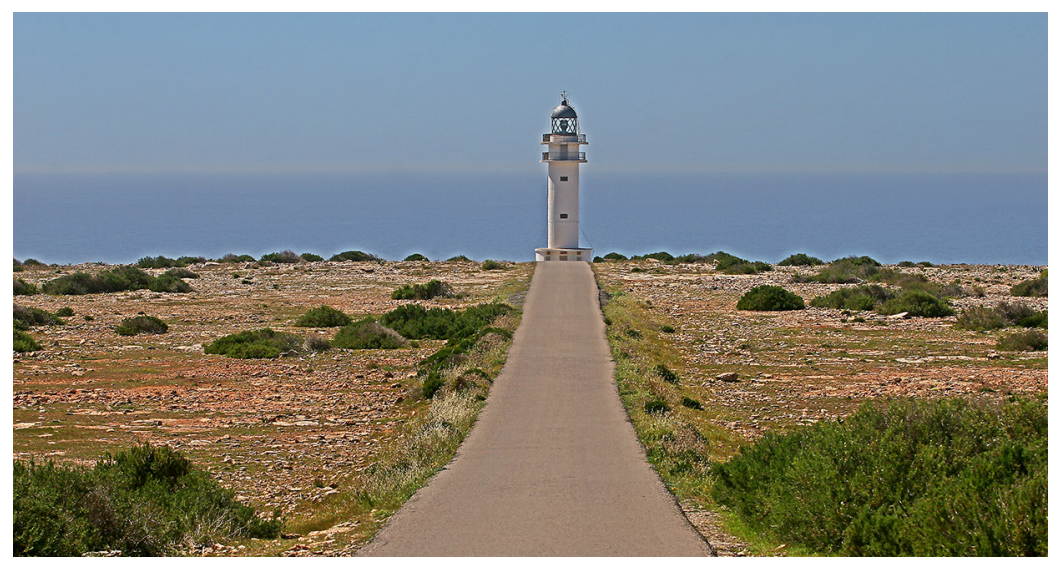

Fotografía de los autores

\subsubsection{Hidrografía}

La toponimia correspondiente a la hidrografía (hidronimia) suma un discreto $8 \%$ del total de los nombres de lugar pitiusos. Se trata de un valor bastante significativo respecto al territorio que describe y que concuerda con las características de un clima mediterráneo de escasas precipitaciones, semiárido, sobre un espacio insular de reducida extensión donde escasean tanto las surgencias de agua como sus breves cursos que, con una sola excepción (Figura 14), permanecen secos la mayor parte del año.

Los hidrónimos pitiusos han sido clasificados (Figura 15) en cinco grupos: masas naturales y artificiales de agua, cursos naturales y artificiales de agua y obras hidráulicas. Encabezan su ponderada clasificación los cursos de agua naturales (60\%) que incluyen esencialmente torrentes y fuentes. Le siguen, con un $28 \%$, las masas de agua naturales que agrupan en su conjunto a albuferas, humedales, marismas, bahías, calas, lagunas, estanques, estrechos y mares, aunque las más abundantes, lógicamente, se refieren a aguas marinas. Sólo un 9\%, también inferior al del conjunto de las Baleares (11,9\%) se refiere a las masas artificiales de agua formadas por pozos, cisternas y depósitos. Finalmente, la obra hidráulica es la que presenta una menor representación toponímica, pues tanto los cursos artificiales (canales y acequias) como el resto (norias) apenas suman el 3\% restante, por debajo de la media insular balear que alcanza el 5,8\%. 
Figura 14. El río de Santa Eulària des Riu —incluido como determinante en el propio topónimo del municipio-, a pesar de su escaso caudal y recorrido, es el único ejemplar en las islas Baleares

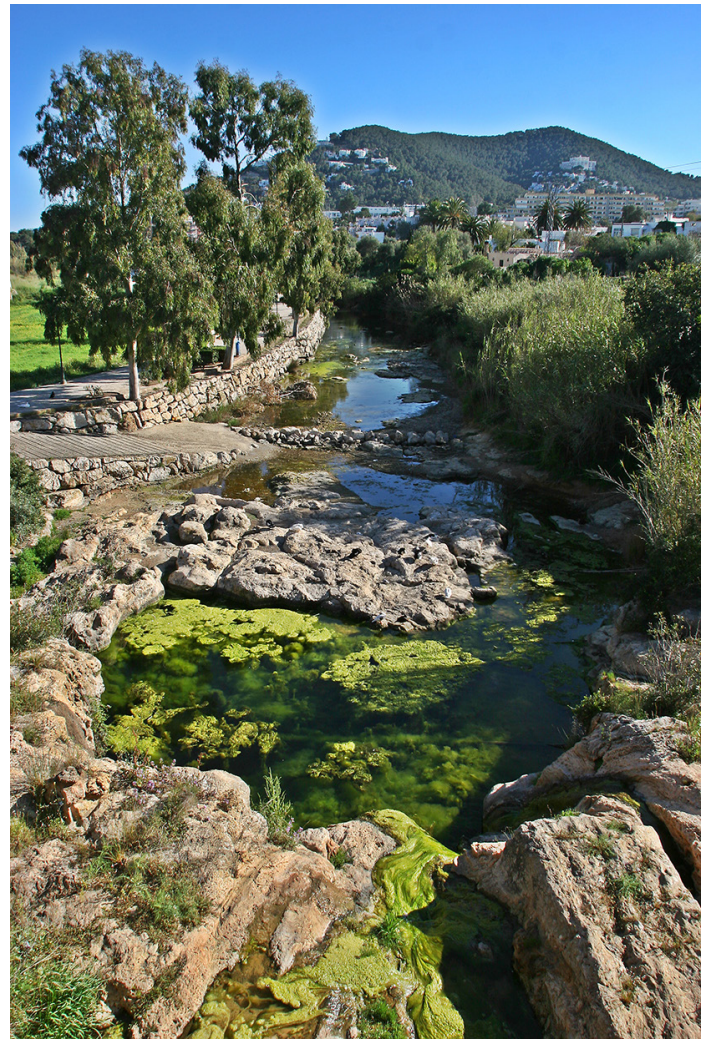

Fotografía de los autores

Figura 15. Toponimia relativa a la hidrografía

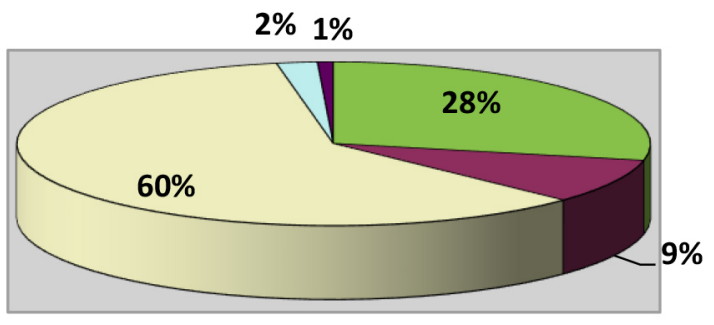

$\square$ Masas naturales de
agua
$\square$ Masas artificiales de
agua
$\square$ Cursos naturales
$\square$ Cursos artificiales
$\square$ Obras hidráulicas

Elaboración propia

\section{Discusión: las singularidades del paisaje pitiuso a través de la jerarquía toponímica}

A partir de las entradas que plantea la codificación del ICC para la toponimia del Mapa Topográfico Balear a escala 1:5.000, se han seleccionado las categorías toponímicas que presentan las mayores frecuencias y se han ordenado de mayor a menor, indicando junto al número de ejemplares, su porcentaje correspondiente con respecto al conjunto de la toponimia isleña. Esta jerarquización (Tabla 3) permite ahondar en la caracterización toponímica y alcanzar un nivel de análisis más detallado. También se ha adscrito cada una de las tipologías toponímicas a una temática definidora de su realidad geográfica, permitiendo distinguir entre topónimos relacionados con la orografía (precisando incluso si es interior o litoral), la hidrografía (natural o humana), la vegetación, el poblamiento y las actividades agrícolas. A partir de una dicotomía básica, se observa cómo las tipologías correspondientes a la toponimia humanizada acumulan un total del $59,4 \%$, frente a las que corresponden a toponimia relativa al medio natural, cuyo porcentaje global es del $31,7 \%$. 
Tabla 3. Pitiusas. Topónimos con mayor número de frecuencias

\begin{tabular}{|c|c|c|c|}
\hline Topónimos & $\begin{array}{l}\text { Número de } \\
\text { frecuencias }\end{array}$ & $\begin{array}{c}\% \text { sobre el } \\
\text { total }\end{array}$ & Adscripción temática \\
\hline Casa (aislada) & 4.106 & 50,9 & Poblamiento \\
\hline Punta, costa & 614 & 7,6 & Orografía litoral \\
\hline Puig, penya, roca & 392 & 4,9 & Orografía interior \\
\hline Torrent, barranc & 300 & 3,7 & Hidrografía natural \\
\hline Parada, camp & 227 & 2,8 & Agricultura \\
\hline Camí, carretera & 200 & 2,5 & Poblamiento \\
\hline Mola, pujol, turó & 167 & 2,1 & Orografía interior \\
\hline Cala & 113 & 1,4 & Orografía litoral \\
\hline Serra & 111 & 1,4 & Orografía interior \\
\hline Vall & 105 & 1,3 & Orografía interior \\
\hline Pla, plana & 82 & 1,0 & Orografía interior \\
\hline Platja & 82 & 1,0 & Orografía litoral \\
\hline Barri, raval & 82 & 1,0 & Poblamiento \\
\hline Cova, forat & 75 & 0,9 & Orografía \\
\hline Illa, illot & 71 & 0,9 & Orografía litoral \\
\hline Cap litoral & 62 & 0,8 & Orografía litoral \\
\hline Escull, faralló & 62 & 0,8 & Orografía litoral \\
\hline Font & 62 & 0,8 & Hidrografía natural \\
\hline Barraca, cabana & 57 & 0,7 & Poblamiento \\
\hline Estany, llacuna & 49 & 0,6 & Hidrografía natural \\
\hline Cisterna & 49 & 0,6 & Hidrografía humana \\
\hline Paratge & 48 & 0,6 & Vegetación \\
\hline Bosc & 43 & 0,5 & Vegetación \\
\hline Solà, solana & 41 & 0,5 & Orografía \\
\hline Hort & 39 & 0,5 & Agricultura \\
\hline Urbanització & 37 & 0,5 & Poblamiento \\
\hline Poble, llogaret & 33 & 0,4 & Poblamiento \\
\hline Coll & 28 & 0,3 & Orografía interior \\
\hline Costa, coster (falda) & 28 & 0,3 & Orografía interior \\
\hline Penya-segat & 27 & 0,3 & Orografía \\
\hline Pont & 27 & 0,3 & Poblamiento \\
\hline Talaia, torre de defensa & 19 & 0,2 & Poblamiento \\
\hline
\end{tabular}

Elaboración propia

En el gráfico de la Figura 16 se jerarquizan las temáticas antes descritas que de alguna manera caracterizan el paisaje pitiuso. La encabezan los topónimos relacionados con el poblamiento que suponen el $61 \%$ de este ranking formado por las 32 tipologías de topónimos con mayores frecuencias. Le siguen, en segunda posición con un $28 \%$, los relativos a la orografía, mayoritariamente litoral frente a la de interior; y la hidrografía (6\%). Algo más lejos quedan los grupos toponímicos relativos a la agricultura (4\%) y la vegetación $(1 \%)$. 
Figura 16. Adscripción temática de la toponimia

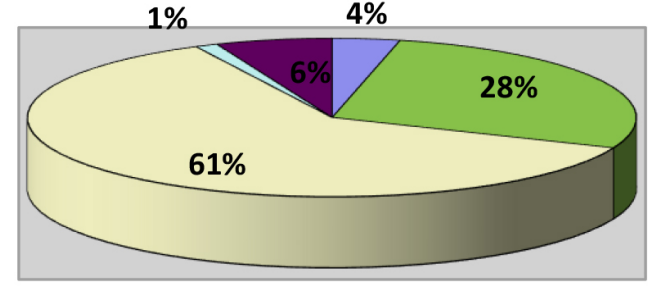

\begin{tabular}{|l|}
\hline Agricultura/Ganadería \\
$\square$ Orografía \\
$\square$ Poblamiento \\
$\square$ Vegetación \\
$\square$ Hidrografía
\end{tabular}

Elaboración propia

Al analizar pormenorizadamente los datos de la Tabla 3, entre los topónimos alusivos al poblamiento destacan sobremanera los referidos a las casas aisladas que pueblan de forma diseminada el territorio pitiuso. Al mismo grupo pertenecen, con una representación mucho más modesta, los nombres relativos a las vías de comunicación (caminos, carreteras y puentes), a barrios o áreas de población, urbanizaciones, pueblos y aldeas, a construcciones modestas (barracas, cabañas) y antiguas construcciones defensivas (torres, atalayas) ubicadas en el litoral por donde tradicionalmente acechaban las peligrosas incursiones de piratas y corsarios.

La oronimia, segundo grupo con mayor representación, también constituye un fiel reflejo del paisaje isleño. De entre el conjunto de los topónimos que identifican la orografía predominan los enclaves litorales a tenor de la considerable longitud de costa (tramos de costa y puntas litorales), otro rasgo sintomático de un entorno isleño de articuladas costas (calas, playas, cabos) y abundantes islas e islotes, además de arrecifes y farallones. No extraña que en el contexto insular abunden, lógicamente, los topónimos litorales, pues el mar resulta determinante en su paisaje y su cultura, en la que destacan los recursos tradicionales de la pesca y, más modernamente, el del turismo de sol y playa, cumpliendo las fases del paisaje de las islas mediterráneas descritas por King (1993). A escasa distancia porcentual se encuentra la oronimia correspondiente al interior insular que nombra todo tipo de relieves de diferentes dimensiones: positivos (puig, penya, roca, serra, talaia, pujol, picatxo, picossa), negativos (canal, coll); horizontales (pla, plana, barda); inclinados (costa, coster) y verticales (acantilados). Bien es cierto que éstos últimos al igual que otros como solana y cova podrían adjudicarse, según cada caso, tanto a la oronimia litoral como a la interior.

En una tercera posición, con una representación muy discreta, se hallan los hidrónimos, tratándose mayoritariamente de torrentes, fuentes y estanques, éstos últimos formando parte de las salinas de Ibiza y Formentera (Figura 17).

Figura 17. La explotación de las salinas de Ibiza se remonta a la dominación cartaginesa de la isla. Junto a las de Formentera han constituido una actividad estratégica y un elemento paisajístico singular

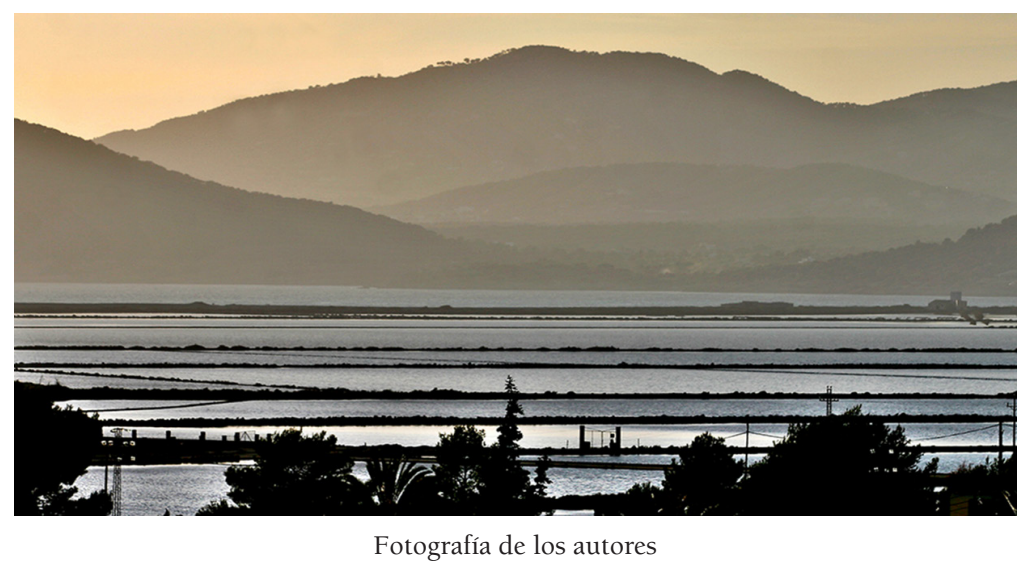

Las alusiones toponímicas a la actividad agrícola son escasas y se reducen a campos y huertos ${ }^{12}$, además de algunos otros genéricos como feixa, terç, rota, tancó y trull. Sólo los fitotopónimos obtienen todavía

12 Relacionada precisamente con la agricultura existe una propuesta etimológica de Formentera, del latín Frumentaria (isla de trigo), abandonada ante la que la empareja lingüísticamente con otro topónimo balear, Formentor. La realidad geográfica de ambos lugares junto con la pronunciación bereber de los marineros árabes que, desde el siglo VII, al escuchar como latinos e hispanos se referían a la isla con el plural Promontoria (que significa 'los dos cabos', refiriéndose al Cap de Barbaria y al Cap de la Mola que destacan en la lejanía), al no tener el sonido de $\mathrm{p}$, lo articulaban como f. 
una menor representación, a pesar de que la masa forestal se halla muy presente en el paisaje. Entre los genéricos fitotoponímicos, no especialmente frecuentes, destaca bosc (bosque), que aquí equivale a pinar (bosque de pinos, Pinus halepensis), término que junto con el de alzinar (encinar, Quercus ilex) no aparecen en la toponimia de Ibiza. Este hecho, sorprendente en el caso del pino por su abundancia (cabe recordar que la hipótesis más aceptada sobre la propia etimología del término Pitiusas la atribuye a los griegos debido al elevado número de pinos que poblaban las dos islas ${ }^{13}$ ), no lo es tanto en el caso de la encina, allí escasa y conocida como bellotera.

\section{Conclusiones: la percepción del paisaje pitiuso a través de su toponimia. Los principios de transparencia y significatividad territorial}

El conjunto de la toponimia describe el paisaje al que designa, proporcionando información detallada sobre múltiples aspectos de los diversos elementos, naturales y humanos, que individualizan cada territorio. Dicha descripción adquiere, además, un sentido diacrónico en su dimensión temporal, de forma que frecuentemente acumula rasgos pretéritos, en una escala temporal diversa que puede comprender conocimientos de culturas y lenguas antiguas hasta incorporar los de otras recientes y contemporáneas. La clasificación y contabilización de la toponimia de las islas Pitiusas confirma estas características y refleja sistemáticamente, mediante la abundancia o repetición, los rasgos más comunes, cumpliendo así el denominado principio de transparencia. No obstante, también se constata el cumplimiento del principio de significatividad territorial por el que se reconocen topónimos de mayor singularidad que recogen aspectos geográficos y paisajísticos relevantes, aunque no siendo tan abundantes, por lo que exigen un cierto grado de conocimiento especializado para ser identificados y correctamente interpretados (Tort, 2003).

El estudio de la terminología geográfica presente en los genéricos toponímicos también permite corroborar y completar los rasgos identitarios y singulares del paisaje y el territorio pitiusos, aun siendo prácticamente inexistentes las diferencias entre Ibiza y Formentera respecto de los genéricos toponímicos, pues la reducida extensión y la tardía ocupación humana de esta última, la convierten en un apéndice de la cercana isla mayor ${ }^{14}$. De este modo, entre los genéricos más emblemáticos cabe citar serra, talaia, puig, pujol, canal, coll, pla, plana, barda, quartó, vénda ${ }^{15}$, feixa, terç, tancó, trull...; mientras otros apelativos son genuinamente pitiusos (albadar, barda, canyer, carnatge, cornetar, empenyalador, encorralador, escala, feixa, joveria, llavessot, llenegador, parancó, picatxo, primall, quintal, quintalar, terç, traguedor, xarco, xiscarra, xuclar); o conllevan acepciones genuinamente pitiusas (alliserany, ansa, bitzarrot, cap, paret, cinta, clotada, contrafita, cordó, covarxa, montgó, muro, penyal). Al margen de esta apreciación sobre la singularidad de los genéricos que denotan la identidad territorial y paisajística, su visión se completa con su jerarquización numérica, siendo los más frecuentes y por este orden: can, cas, puig, costa, torre, punta, torrent, canal, pla, pujol, cal, camí, racó, serra, cala, cova, cap y platja.

El análisis de los genéricos presentes en los topónimos pitiusos así como de su intensidad o frecuencia, permite descubrir una clara correspondencia con los rasgos fundamentales del espacio geográfico al que pertenecen. El elevado nivel de rururbanización y urbanización turística en comparación con el resto de las Baleares queda así reflejado en la toponimia, postergando a una posición secundaria desde un punto de vista cuantitativo a otros aspectos físicos del paisaje y, especialmente, a los orónimos, a pesar de ser relativamente numerosos. Entre ellos, destaca el apelativo canal que aparece fuertemente extendido por toda la isla de Ibiza constituyéndose en el máximo representante de las depresiones alargadas situadas en las faldas montañosas. Las prominencias orográficas de interior son denominadas preferentemente mediante los genéricos puig, pujol y serra, mientras que en el litoral abundan punta, racó, cala, cap y platja.

13 De pitys, pino en griego, derivaría Pitioussa, según el autor clásico Diodoro. También los romanos, como Plinio el Viejo, comentaron la abundante población de pinos de las islas. No obstante, existen otras hipótesis como la que la relaciona con los seguidores de un culto a un dios vencedor de la serpiente (Python). De este modo, se conectarían los antiguos topónimos de Ibiza y Formentera (Pythiusa y Ophiusa), ésta última por la abundancia de ofidios (serpientes).

14 Tanto es así que durante un largo período histórico la isla de Formentera estuvo adscrita administrativamente al municipio de Ibiza.

15 Quartó y vénda son términos históricos de origen medieval, propios de la división territorial y administrativa de Ibiza que han perdurado hasta día de hoy. 
De todo ello se infiere, como principal rasgo de la toponimia pitiusa, la considerable presencia ${ }^{16}$ de las partículas indicadoras de vivienda (Can, Cas y Cal) ${ }^{17}$, acompañadas de antropónimo. Moreu-Rey (1982) apuntaba que la proporción de antropotopónimos, o topónimos procedentes de antropónimo, es extraordinaria en todos los países y en cualquier época, estimando que en algunas regiones su proporción podía superar el 40 o 50\% del total de topónimos. El caso pitiuso lo demuestra claramente, al exceder dichas estimaciones, debido a dos factores: un minifundismo ligado al crecimiento demográfico y a un tipo de poblamiento en diseminado que incide sobre el elevado número de topónimos relativos a nombres de casa; y la repetición de los mismos apellidos -agravada por la tradición de reproducir los mismos nombres de persona, generación tras generación-, que inutiliza la antroponimia legal, de forma que la fórmula 'nombre-apellido' pierde la capacidad de distinguir entre los numerosos individuos con designación homónima, fenómeno muy extendido en Ibiza y Formentera. Se comprueba como en las islas menores se intensifica el carácter endogámico de la sociedad y que se refleja en la antropotoponimia que aparece en la designación toponímica de la propiedad y de los nombres de casa. Un reducido grupo de genéricos (finca, hisenda, pallissa/ paissa y casilla) completan la temática poblacional a la que se puede añadir aún el genérico torre (Figura 18), cuyas funciones de vigilancia y defensa de la costa resultaron imprescindibles durante siglos. No es casualidad que algunas de las cimas de la isla se denominen mediante el genérico talai $a^{18}$, definido como un lugar elevado apropiado para la observación y desde donde dar aviso de lo que se aviste.

Figura 18. Desde la torre des Savinar se divisan los islotes de es Vedrà y es Vedranell, configurando uno de los paisajes más emblemáticos del litoral ibicenco

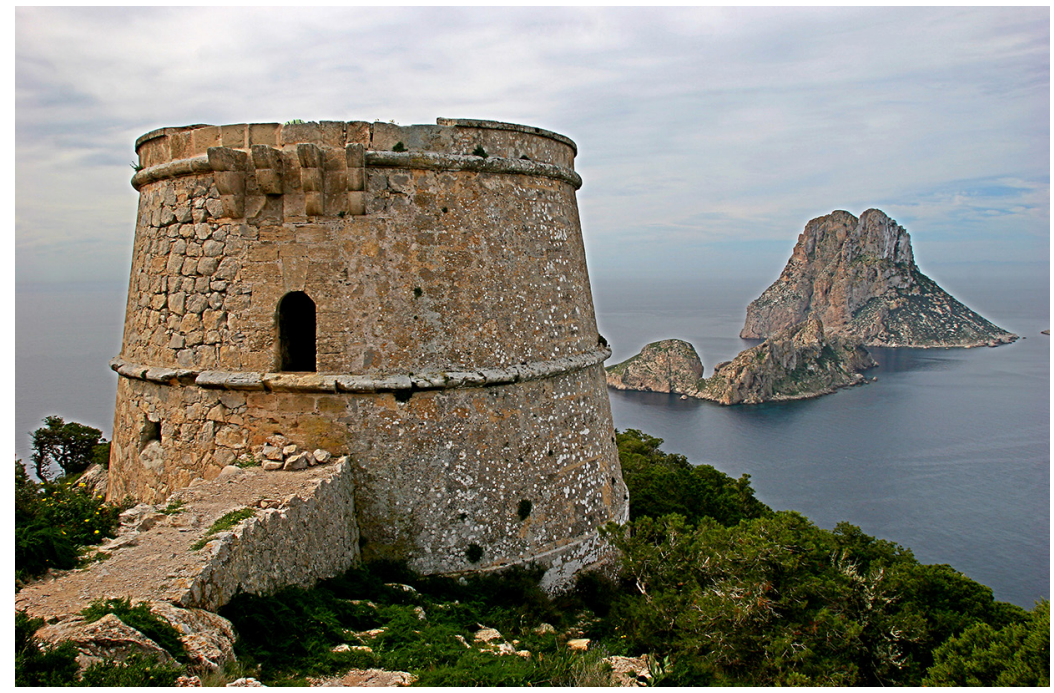

Fotografía de los autores

En conclusión, se constata la reciprocidad entre la toponimia de las islas de Ibiza y Formentera y la geografía de sus paisajes, crisol de una cultura milenaria en la que se conjuga el testimonio secular de los diversos pueblos mediterráneos y sus respectivas lenguas y costumbres. Su huella en unas tierras cuyos nombres identifican una clara personalidad —incluso en el conjunto del archipiélago balear-, todavía perdura a pesar de la amenaza culturalmente uniformadora que supone el turismo cosmopolita en la era de la globalización.

\section{Referencias}

Aguiló, C. (1986). Primera aproximació a la toponímia d'es Vedrà i es Vedranell. Estudis Baleàrics, 20, 53-62.

16 Dicha abundancia contrasta con la ausencia de la partícula Son, partícula también indicadora de propiedad muy presente en Mallorca y, en menor medida, en Menorca.

17 Fórmulas sincopadas de Ca (casa de) + en/es/el (artículos en sus variedades pronominal y determinados derivados del latín ipse o ille, que anteceden un antropónimo, ya sea en forma de nombre de pila, apellido o apodo personal o familiar).

18 Talaia de Sant Josep, Talaia de Jesús, Talaia de Sant Vicent, Talaia de Sant Llorenç, Talaia de Sant Joan, Talaia de Sant Antoni son algunos ejemplos. 
Aguiló, C. (1987). Mapa toponímic dels illots de les Pitiüses. Inca: Direcció General de Cultura. Conselleria de Cultura del Govern Balear-Universitat de les Illes Balears.

Aguiló, C. (1989). Mostra toponímica del litoral de les Pitiüses (I i II). El Mirall, 25, 20-25. 26, 26-30.

Aguiló, C. (1990). Dos glosats sobre l'illa des Vedrà. Notes a l'entorn de la seva toponímia. El Mirall, 34, 71-74.

Aguiló, C. (1993a). Els reculls exhaustius de toponímia a les illes Balears i Pitiüses. Butlletí Interior Societat d'Onomàstica, LIII, 143-147.

Aguiló, C. (1993b). Breus comentaris sobre el nom de s'llla de Casteví. Eivissa, 23, 14-15.

Arroyo, F. (2010). Creciente interés geográfico por la toponímia. Estudios Geográficos, LXXI(268), 299309. https://doi.org/10.3989/estgeogr.0600

Caldentey, J., Grimalt, M. y Ordinas, A. (2006). El paisatge vitícola actual i històric de Mallorca a través de la toponímia. En XVIII Jornada d'Antroponímia i Toponímia (2005) (pp. 63-70). Universitat de les Illes Balears.

Castelló, J. (1963). La toponimia de Ibiza y Formentera. Boletín de la Cámara de Comercio, Industria y Navegación, 639, 71-85.

Fernández Álvarez, R., Gómez-Gonçalves, A. y Luengo Ungidos Correo, M. Á. (2019). Aprendiendo a interpretar el territorio: estudio de la fitotoponimia en la provincia de Salamanca. Boletín de la Asociación de Geógrafos Españoles, 82, 2816, 1-33. http://dx.doi.org/10.21138/bage.2816

Grimalt, M., Ordinas, A. y Caldentey, J. (2009). El paisatge vegetal de Menorca a través de la fitotoponímia. Documents d'Anàlisi Geogràfica, 55, 93-115. Recuperado de https://www.raco.cat/index.php/ DocumentsAnalisi/article/view/171751

Gordillo, J. L. (1981). Sobre la toponimia formenterera. Formentera, Historia de una isla. Valencia: Ed. Albatros.

King, R. (1993). The Geographical Fascination of Islands. In D.G. Lockhart, D. Drakakis-Smith, \& J.A. Schembri, (Eds.), The Development process in Small Islands State. (pp. 13-37). London: Routledge.

Macabich, I. (1966a). Toponimia Románica. En Historia de Ibiza (4 vol), (I, pp. 74-83). Palma de Mallorca: Ed. Daedalus.

Macabich, I. (1966b). Etimologías. En Historia de Ibiza, (4 vol), (I, p. 83). Palma de Mallorca: Ed. Daedalus.

Macabich, I. (1966c). ¿Es la cueva dels Cuyeram o des Cuiram?. En Historia de Ibiza, (4 vol), (I, pp. 138139). Palma de Mallorca: Ed. Daedalus.

Macabich, I. (1966d). Origen del vocablo "venda". En Historia de Ibiza, (4 vol), (IV, pp. 398-401). Palma de Mallorca: Ed. Daedalus.

Macabich, I. (1966e). Etimología de Bisalba. En Historia de Ibiza, (4 vol), (IV, p. 394). Palma de Mallorca: Ed. Daedalus.

Macabich, I. (1966f). Sobre Espalmador, Espardell, Espartar. En Historia de Ibiza, (4 vol), (IV, pp. 409410) Palma de Mallorca: Ed. Daedalus.

Macabich, I. (1966g). Etimología de Feixes. En Historia de Ibiza, (4 vol), (IV, pp. 411-412). Palma de Mallorca: Ed. Daedalus.

Macabich, I. (1966h). Ibiza de Ebusus o estéril en fenicio, un disparate. En Historia de Ibiza, (4 vol), (IV, pp. 418-419). Palma de Mallorca: Ed. Daedalus.

Macabich, I. (1966i). Término o voz «so» significado de campo o propiedad rústica. En Historia de Ibiza, (4 vol), (IV, pp. 417-428). Palma de Mallorca: Ed. Daedalus.

Marí, I. (1979). Toponímia bàsica de les Pitiüses. Cap a la normalització dels noms de lloc. Lluc, 685, $15-16$.

Marí, J. (1991). Supervivència de noms dels segles XIII-XIV: Portmany. Eivissa, 19-20, 33-37.

Martínez, S. y Epalza, M. de (1987). Sobre la arabización de los nombres de las Islas Baleares: Maiorica, Minorica, Ebusa-Ebisa, Furmentera-Formentera. En V Jornades d'Estudis històrics locals (pp. 173179). Palma de Mallorca. 
Martínez de Pisón, E. (2010). Valores e identidades. En E. Martínez de Pisón y N.Ortega Cantero (Eds.), El paisaje: valores e identidades (pp. 11-45). Madrid: Ediciones de la Universidad Autónoma de Madrid.

Mateu, J.F. (2000). Vicenç M. Rosselló i la toponomàstica valenciana. En Estudis de Toponímia Valenciana (pp. 1-9). Valencia: Ed. Denes.

Moreu Rey, E. (1982). Els nostres noms de lloc. Palma de Mallorca: Ed. Moll.

Ordinas, A. (1994). Malnomenació a l'antropotoponímia pitiüsa. Una aproximació al cas de Formentera. Butlletí Interior de la Societat d'Onomàstica, LIX, 85-90.

Ordinas, A. (1998). Cartografia i toponimia. Col. Ciències Socials a les Illes Balears. Bibliografia bàsica, 1. Conselleria d'Educació, Cultura i Esports del Govern Balear.

Ordinas, A. y Binimelis, J. (2013). La caracterización del paisaje de Menorca a través de la toponimia. Investigaciones Geográficas, (60), 155-169. https://doi.org/10.14198/INGEO2013.60.09

Ordinas, A. y Binimelis, J. (2020). Sacando los colores al paisaje. La cromotoponimia de las islas Baleares. Disparidades. Revista de Antropología, 75(1), 1-16. https://doi.org/10.3989/dra.2020.012

Picornell, C. (1982). La nova toponímia de les Illes Balears. Una aportació als topònims sorgits arrel del turismo. Societat d'Onomàstica. Butlletí Interior, X, 86-100.

Poveda, A. (1984). Sobre los distritos, las explotaciones y la toponimia clánica de Yabisa (Eivissa). Estudios Árabes, 1.

Ribes, E. (1986). Es Vedrà: a la recerca d'una etimologia. Es Vedrà i es Vedranell, 36, 7-9.

Ribes, E. (1991). Beniformiga i les Formigues. Diario de Ibiza, 25/08 y 1/09, Eivissa.

Ribes, E. (1992a). Noms de lloc. Toponímia de les Pitiüses. Ibiza: Ed. Can Sifre. (Col-lecció Arxipèlag; 2).

Ribes, E. (1992b). L'Illa d'Encalders: el curiós origen d'un topònim eivissenc. Eivissa, 22, 44-47.

Ribes, E. (1992c). L'Illot de l'Ora. El Pitiús 1993. Ibiza: Institut d'Estudis Eivissencs.

Ribes, E. (1993a). Alguns noms de les cavitats a la roca en la toponímia eivissenca. Eivissa, 23, 32-35.

Ribes, E. (1993b). Sobre l'etimologia del Vedrà. Eivissa, 24, 35-37.

Ribes, E. (1993c). Els genèrics en la toponímia de Formentera. En El Pitiús 1994 (pp. 45-47). Ibiza.

Ribes, E. (1993d). La toponímia de la costa de Sant Joan de Labritja. Ibiza: Edicions Can Sifre.

Ribes, E. (1995). La toponímia de la costa de Sant Antoni de Portmany. Palma: Institut d'Estudis Baleàrics.

Ribes, E. (2006). La toponímia costanera del municipi d'Eivissa. Ibiza: Mediterrània-Eivissa.

Riesco, P. (2010). Nombres en el paisaje: la toponímia, Fuente de conocimiento y aprecio del territorio. Cuadernos Geográficos, 46(2010-1), 7-34. https://doi.org/10.30827/cuadgeo.v46i0.629

Torres, M. (1987). Aportació a la toponímia de les Pitiüses: es Broll de Buscastell i es Pla de Portmany. Eivissa, 17-18, 22-27.

Torres, M. (1995). Toponímia i escola: una proposta didàctica. Eivissa, 26, 20-23.

Tort, J. (2001). La toponímia com a camp de coneixement interdisciplinari. Algunes bases teòriques i epistemològiques per a l'estudi dels noms de lloc. Scripta Nova, 86. Recuperado de http://www.ub.edu/ geocrit/sn-86.htm

Tort, J. (2003). A propòsit de la relació entre toponímia i geografia: el principi de 'significativitat territorial'. En E. Casanova y L.R. Valero (Eds.), XXIX Col-loqui de la Societat d'Onomàstica (pp. 675-688). Teulada: Ed. Denes.

Villangomez, M. (1969). Sobre el nom de la ciutat més antiga de les Illes (Eivissa). Lluc, 134.

Villangomez, M. (1977a). Sobre Cap Nunó i dos noms més. Uc, setmanari d’informació general. 13, 34.

Villangomez, M. (1977b). Mapes i topònims: Ses Salines. Uc, setmanari d’informació general. 11, 32. 